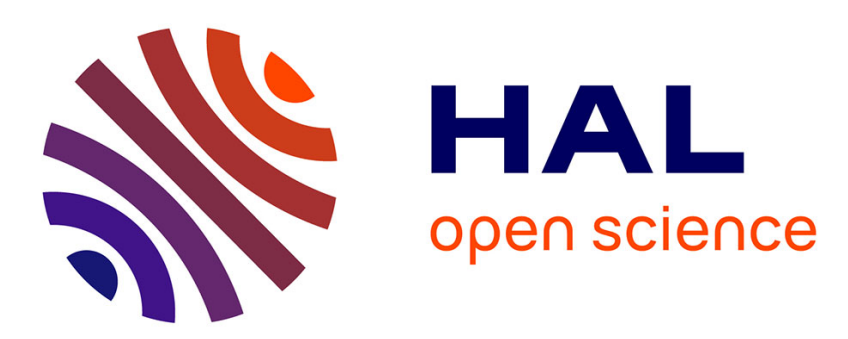

\title{
The adaptation process of international lecturers in a South African university: The centrality of agency and collegiality
}

\author{
Loïse Jeannin
}

\section{To cite this version:}

Loïse Jeannin. The adaptation process of international lecturers in a South African university: The centrality of agency and collegiality. Journal of Research in International Education, 2017, 16 (3), pp.236 - 247. 10.1177/1475240917746035 . hal-01892135

\section{HAL Id: hal-01892135 \\ https://hal.science/hal-01892135}

Submitted on 3 Dec 2018

HAL is a multi-disciplinary open access archive for the deposit and dissemination of scientific research documents, whether they are published or not. The documents may come from teaching and research institutions in France or abroad, or from public or private research centers.
L'archive ouverte pluridisciplinaire HAL, est destinée au dépôt et à la diffusion de documents scientifiques de niveau recherche, publiés ou non, émanant des établissements d'enseignement et de recherche français ou étrangers, des laboratoires publics ou privés. 


\title{
The adaptation process of international lecturers in a South African university: The centrality of agency and collegiality ${ }^{*}$
}

\section{Loïse Jeannin}

University of Johannesburg, South Africa

\begin{abstract}
Teaching in a new country initiates a process of adaptation requiring emotional, cognitive and behavioural adjustments. This qualitative study explores international lecturers' perceptions of their adaptation process in a South African university. The findings, based on semi-structured interviews with six lecturers from six different countries, indicate that teachers' agency and collegiality are crucial interrelated factors of adaptation. Agency and collegiality enabled lecturers to receive contextrelevant information and decide how to modify their pedagogical practices. The description of the adaptation process provides new insights for staff induction programmes.
\end{abstract}

\section{Keywords}

Adaptation process, agency, collegiality, internationalisation, teacher development, transformative learning

* Jeannin, L. (2017). The adaptation process of international lecturers in a South African university: The centrality of agency and collegiality. Journal of Research in International Education, 16(3), 236-247. https://doi.org/10.1177/1475240917746035 


\section{INTRODUCTION}

The experience of teaching abroad offers an opportunity for personal and professional learning that has been explored in the literature under the notions of sociocultural adaptation and transformative learning (Kim, 2008; Volet and Jones, 2012). University lecturers are indeed exposed to different learning habits, teaching expectations and communication styles throughout their international experiences and they may be ill-prepared for the challenges brought by international exposure (Cai and Hall, 2016; Deveney, 2007). While academic mobility is rising internationally, the adaptation process of international lecturers has not received enough attention. It is however crucial to understand the adaptation process of international staff to facilitate their adjustment, increase their preparedness and support their teaching effectiveness (Korhonen and Weil, 2015; Mizzi, 2017; Shafaei and Razak, 2016; Volet and Jones, 2012).

This paper does not approach international lecturers' adaptation in terms of lack or gaps; on the contrary, it considers the adaptation process as an opportunity to grow professionally. As argued by Clegg (2011), transnational lecturers come with a set of capabilities in addition to social, economic and cultural capital from which they can draw to adjust and negotiate space and power in a new organisation. As a result, adaptation is the process by which individuals change their behaviours, frames of reference, and identity to match the requirements of their new environment (Kim, 2008; Tran, 2008) while relying on their own experiences, capabilities and agency (Lai et al., 2016). The adaptation process is described as the emotional, behavioural and cognitive adjustments that are necessary to meet the expectations of new students and administration. It can be analysed in terms of boundary crossing, experiences of discontinuity and stress, resilience and identity re-negotiation 
(Akkerman and Bakker, 2011; Kim, 2008; Parr, 2012; Volet and Jones, 2012; Williams and Berry, 2016).

There is a debate in the literature with regard to the scope of the adaptation of international lecturers (Lai et al., 2016; Smith, 2014; Volet and Jones, 2012; Zhou and Todman, 2008); to what extent do lecturers adjust to, or on the other hand modify, their teaching context? Do they experience a unilateral or reciprocal process of adaptation? In some studies, teachers' adaptation is presented as a reciprocal process of adjustments entailing changes from teachers and students (Tran, 2008; Volet and Jones, 2012; Zhou and Todman, 2008). Other studies have shown that international lecturers tend to change themselves more than they affect their new teaching context, eliciting a unilateral process of adaptation (Lai et al., 2016). This paper aims to contribute to this unilateral-reciprocal debate by analysing the adaptation process of six international lecturers in a South African university.

The study is relevant to the South African context where it contributes to the debates around the internationalisation of higher education (Cross et al., 2009; Kishun, 2007; Teferra and Knight, 2008). As South African universities attract increasing numbers of international staff, studying the adaptation process of international lecturers becomes crucial considering the complexity of the South African context. International lecturers are confronted with the specificity of the post-apartheid socioeconomic context and the new organisational culture (Sing, 2006). As a result, this qualitative study aims to identify the salient aspects of the adaptation process of international lecturers in one specific university in South Africa. It revolves around two research questions:

- How did international lecturers perceive their adaptation process during their first months of teaching in the university?

- Which factors did international lecturers identify as affecting their adaptation process? 
After a review of the literature on adaptation and a presentation of the theoretical framework, the methodology section will detail the specificity of the university and the procedure used to recruit participants. The findings are organised around two themes characterising foreign teachers' perceptions of their adaptation process: (i) A sequential and unilateral process of adaptation and (ii) the interrelation between agency and collegiality as prominent factors of adaptation. These themes are directly linked to the research questions presented above.

\section{ADAPTATION TO NEW SOCIOCULTURAL CONTEXTS: INSIGHTS FROM THE}

\section{LITERATURE}

In the literature, the adaptation process is described as a re-balancing process after a rupture or a crisis (Hviid and Zittoun, 2008; Volet and Jones, 2012) in accordance with models of culture shock (Dongfeng, 2012; Roskell, 2013). For example, Kim (2008) approached the adaptation process as a three-stage dynamic process based on stress, adaptation and growth. Stress occurs with the experience of confusion in a new cultural environment. In other studies (Akkerman and Bakker, 2011; Mizzi, 2017; Williams and Berry, 2016), sociocultural adaptation is conceptualised in terms of boundary crossing and self-repositioning. Physical, cognitive and behavioural boundaries are crossed when individuals are exposed to new cultural minds and behaviours.

Crossing boundaries offers the opportunity to learn professionally, to fit into different cultural spaces and ultimately to grow personally. As a result of their experiences abroad, international lecturers can free themselves from sociocultural beliefs, change their behaviours and reconsider their professional identity (Akkerman and Bakker, 2011; Kim, 2008). Drawing on the positioning theory of Van Langenhove and Harré (1999), Tran (2008) explored the process of re-positioning of seven international students and four lecturers in Australia. As students were searching for congruence and class belonging, they changed their behaviours 
and discourses as a result of their international exposure. Although the study explored the adaptation process of students rather than university lecturers, three modes of adaptation described by Tran were informative for the research described in this paper: surface adaptation, committed adaptation and hybrid adaptation.

Firstly, surface adaptation occurred when students' values and aspirations were not in harmony with the new class expectations in Australia (Tran, 2008). As a consequence, students changed their behaviours to comply with the rules without appropriating them. More precisely, surface adaptation related to the self-forced positioning scenario of Van Langenhove and Harré (1999) which can be described as an effort towards conformity. Secondly, Tran (2008) pointed out behaviours of committed adaptation that required deeper engagement than surface adaptation. Committed adaptation resulted from a desire to adopt new values and behaviours in replacement of previous values and practices. It can be related to the self-positioning scenario of Van Langenhove and Harré. Finally, some students demonstrated hybrid adaptation, falling in between the continuum of surface and committed adaptation. Hybrid adaptation was a process by which students adjusted to the requirements of the site while using their agency to express themselves and remain congruent to their values and beliefs.

Volet and Jones (2012) produced an extensive literature review on the sociocultural adaptation process of students and teachers immersed in culturally diverse environments. The researchers discussed the unilateral, bilateral and reciprocal adaptation processes based on stakeholders' negotiation and dialogues. In the reciprocal approach, teachers and students, both local and international, co-negotiate the nature of their interactions as teachers and students bring their own perspectives and expectations into the classroom (Volet and Jones, 2012). In essence, teachers adjust to students' learning expectations while in return students adapt to the instructors' teaching and learning expectations. 
Finally, in a four-year self-study, Williams and Berry (2016) reflected on their learning experiences and identity changes as a result of their international exposure. Using their personal learning journals, the authors analysed their teaching experiences through critical incidents and boundary crossing (Akkerman and Bakker, 2011). They contended that crossing physical, cultural, personal, professional and linguistic boundaries exposed them to experiences of discontinuity and confusion that encouraged their self-reflection. Williams and Berry reflected on the multiplicity of their roles in international contexts and the renegotiation of their roles and identity with their colleagues. As a result, the diverse lenses presented in this section highlight the multidimensionality of the adaptation process, including discontinuity, coping strategies, professional learning and identity changes. The next section introduces the conceptual framework that was used to develop the research methodology of the study.

\section{CONCEPTUAL FRAMEWORK}

The conceptual framework of this study drew on the transformative learning theory (Mezirow, 1991, 2012; Mezirow and Associates, 2010) to unfold the experiences of international faculty members. In the transformative learning theory, learning is an ongoing process triggered by unsettling and confusing experiences known as disorienting dilemmas. These disorienting dilemmas invite teachers to reflect on their practices and engage in dialogues (Mezirow, 1991, 2012). The learning process occurs through self-reflection and critical dialogues that expand teachers' frames of reference by integrating new ideas, values and beliefs.

The exposure to new and multicultural environments can be a source of disorienting dilemmas, prompting a process of transformative learning (Mezirow, 1991; Volet and Jones, 2012). As lecturers have acquired teaching habits from their previous studies and experiences, they may face challenges when teaching abroad (Green and Myatt, 2011; Niyubahwe et al., 
2014; Smith, 2013, 2014; Walker, 2015). These challenges come from the gap between their previous practices and the new site requirements (Mizzi, 2017). A first exposure to different student learning behaviours and new administrative assignments may create disorienting dilemmas (Smith, 2013, 2014), while a lack of understanding of the national and local cultures could generate misunderstandings (Gopal, 2011; Walker, 2015).

\section{METHODOLOGY}

The university under study is a large university in Johannesburg (South Africa) with a diverse population of students and lecturers in terms of sociocultural and linguistic backgrounds. Classes usually take place in large classrooms with 200 to 400 students. A maximum variation sampling strategy was chosen to embrace the diversity of experiences of international lecturers in the university. The selection criteria were the following: (i) being non-South African; (ii) having taught for at least 10 months in the university; and (iii) having taught in another country before coming to South Africa. The 10-month limit was arbitrarily chosen to ensure that a large number of lecturers could participate in the study, but also to ensure that respondents had been teaching in the university long enough to be able to reflect on their adaptation process. The fact that respondents had taught in another country before coming to South Africa meant they could compare their South African teaching experience with another cultural context and, due to this comparative experience, they were expected to bring rich information and reflective thoughts during the interview.

The six participants were one female and five male lecturers in varying academic departments who had been working for the university between one and nine years. They reported different cultural and linguistic backgrounds, coming from five different countries in Africa and one in Europe (French- or English-speaking countries). Countries are not revealed to protect respondents' confidentiality, and pseudonyms are used to report the findings. All participants had taught in their country of origin for no more than four years before coming to 
South Africa. As a consequence, they all had a previous teaching experience in another country which could have influenced their expectations when starting teaching in Johannesburg. After receiving institutional ethical clearance for this study, an email was sent to potential respondents to invite them to participate in the research. Consent forms were used to inform participants about their rights. An interview protocol was developed to encourage respondents' reflections and to collect their perceptions of the adaptation process in the university. It had been reviewed by an external international scholar to enhance its validity.

Interviews were conducted face-to-face in each lecturer's office (five participants) or by email (one participant) between June and September 2016. Face-to-face interviews, from 30 to 50 minutes, were recorded and transcribed. The option of answering by email (at any time) was offered to accommodate participants as it reduced the time burden of being interviewed face-to-face (Meho, 2006). Only one participant chose this interview method. The coding procedure adopted as the basis for analysing interview data aimed at revealing codes and themes that characterised the adaptation processes. Hand coding consisted of labelling sentences with codes that emerged iteratively and were refined throughout the data analysis (Creswell, 2012; Lodico et al., 2010). These emerging codes pertained to emotions and the adaptation process steps, factors and consequences.

As a means of enhancing the reliability of the findings, participants were able to review the findings including verbatim quotes of their interview and to comment or add clarifications. This procedure helped validate the accuracy and credibility of the findings, which are presented in the next section. As the sample included only six international lecturers, the qualitative findings cannot be taken as representative of the experiences of all international lecturers in the university. However, the findings provide an initial understanding of lecturers' experiences in this context. Negative case analysis was given particular attention to embrace the complexity of lecturers' experiences. 


\section{FINDINGS: AN ADAPTATION PROCESS BASED ON AGENCY AND}

\section{COLLEGIALITY}

Reflecting on their first months of teaching, the six participants reported intertwined feelings that triggered some reflections, decisions and actions. Their perceptions are organised around two overarching themes in order to answer the research questions. These are: (i) a sequential and unilateral process of adaptation; and (ii) the interrelation between agency and collegiality in the adaptation process. It is important to note that the respondents constituted a diverse group in terms of nationalities, ages, gender and distinctive experiences. The necessity to adjust and the scope of the adaptation process were not perceived with the same intensity by all respondents, but the steps and the factors of adaptation presented below are common to their experiences.

\section{Theme 1: A sequential and unilateral process of adaptation}

This theme answers the first research question: How did international lecturers perceive their adaptation process during their first months of teaching in the university? The narratives of participants permitted the identification of the steps and characteristics of the adaptation process that resulted from their teaching experience in the university. Five important moments were identified along the process, as detailed in Figure 1. These include: a. Disruption: new and disorienting experiences, sometimes with negative emotions; b. Search for information and collegial support; c. Understanding, acceptance and decision-making; d. Pedagogical changes and professional learning; and, sometimes, e. A sense of achievement and satisfaction. Within this process, faculty collegiality and teacher agency played a major role. The adaptation was presented as a unilateral process rather than a reciprocal process, as lecturers stressed how they learned and changed rather than how other stakeholders adjusted to their ways of teaching. 
Insert Figure 1 about here

The adaptation steps. According to participants, the foundations of adaptation rest on understanding the context, accepting it and learning new pedagogical practices. Adaptation started with disorienting experiences and feelings of confusion due to the differences between what they observed in their new environment and what they were used to in their previous teaching location. After identifying the differences, lecturers started seeking information, explanations and support from colleagues. Through collegial discussions within their department, lecturers managed to make sense of their new teaching experiences. They ended up accepting the university stakeholders' requirements while modifying their teaching behaviours to meet the learning needs of their new students.

This process was fully consistent with Mezirow's $(1991,2012)$ transformative learning theory, thereby confirming its validity in this context. As a result of their professional learning, some international lecturers reported a sense of achievement and satisfaction regarding their teaching efficacy in this new environment. The successive adaptation steps are further detailed in the following paragraphs.

Some lecturers reported experiences of surprise and disappointment when starting teaching in the university. They indicated being surprised by some aspects of the organisational culture and the diversity of student backgrounds that they related to the legacy of apartheid. Respondents realised they were not holding the same beliefs and learning expectations as their South African students and colleagues. Their constructed realities differed and their expectations with regard to students' learning habits and motivation were not always met. For example, Philip compared students in the South African university with students in his previous teaching location (abroad): 'For me, it was a culture shock, because I came with the expectation of competencies that university students should have. Then, you get to university and all your expectations are proven wrong'. These disorienting experiences 
sometimes created negative emotions that served as a trigger for the development of coping strategies.

Some respondents initially felt disappointed or overwhelmed because of the differences between their new students and the students in their country of origin. They did not expect the diversity of English language proficiency levels and the consequences of sociocultural disparities that resulted from South Africa's history. Some lecturers explained that they expected their students to be more independent, hardworking or intrinsically interested in the topic than they turned out to be. In addition, several lecturers, especially from French-speaking countries, reported being exposed to a new teaching culture centred on students' learning needs when they were used to teacher-centred approaches. This provoked a paradigm shift for some of them. Because of this initial feeling of confusion or bewilderment, lecturers initiated a search for information and advice from colleagues. The community of teachers provided information enabling participants to decode their new teaching environment and understand students' learning needs. As a result, the support received from colleagues lowered teachers' anxiety.

To better focus on students' learning needs and match the site requirements (in terms of content and pedagogy), international lecturers enacted pedagogical changes. For example, they learned how to manage students' diversity in terms of knowledge competencies. Allan explained:

There is a general difference with [country's name] that is the diversity of student family, educational and emotional background. This needs to be considered by the lecturer. During practice, this means the lecturer has to be stretched between entertaining the top students so they don't feel bored, and being slow enough to the bottom students so they are not left behind.

Participants ended up learning new skills to manage their large classes (200 to 400 students), improving their communication skills in a foreign language (English) and increasing their patience. Allan noted that he is 'more patient than before [and] less 
overwhelmed by the diversity and the disadvantaged background of some of the students'. This learning process induced an increased sense of achievement and satisfaction. Philip explained, 'it was ... very fulfilling when you take students from ... one level to a higher level. So, there is also that sense of fulfilment, achievement, accomplishment ... during the first semester'. As a result, through their new understanding of students' backgrounds and contextual codes, respondents developed their pedagogical practices to better meet their students' learning needs. The adaptation process schematised in this section included the important steps of adaptation reported by lecturers. The next paragraphs present how lecturers perceived their adaptation as a rather unilateral and continuous process of class improvements.

A unilateral and continuous process of adaptation. Three lecturers stressed that class improvement was a continuous process. Every semester, lecturers aimed to improve their courses and enhance students' learning experiences. Their adaptation to the site's requirements was actually the beginning of a continuous professional learning process in the university. Lee clarified this point: 'Every time I adjust ... In 2015, I changed the content; this year, I have identified the assessment techniques, so it is an ongoing process, adjustment is still ongoing'. As a result, and in accordance with dynamic models of adaptation (Kim, 2008), the adaptation process of international lecturers is an initial sequence in the ongoing process of class improvements and pedagogical skill development.

As with Lai et al.'s findings (2016), the adaptation process reported by lecturers is mainly unilateral. International lecturers felt they adapted their teaching practices to meet the requirements of their administration and students' needs. They did not report any reciprocal adaptation whereby different stakeholders changed their behaviours as a result of their interactions (Volet and Jones, 2012). However, this perception of unilateral adaptation does not mean that lecturers felt left alone in the process. On the contrary, they reported benefitting from the support of their academic colleagues. It means that lecturers perceived their own process of adjustments irrespective of the adaptation that may have occurred from other stakeholders (from the students or from the administration). Further 
study could compare international lecturers' perceptions with the experiences of their local colleagues, students and administration in order to gain a more comprehensive picture of the effects of international lecturers on their host universities.

The second theme of the findings is related to the factors of adaptation that supported lecturers' adjustments. As participants retrospectively made sense of their adaptation, two major factors were prominent: lecturers' agency and faculty collegiality. These are described in this last subsection.

\section{Theme 2: The interrelation between agency and collegiality}

This theme addresses the second research question: Which factors did international lecturers identify as affecting their adaptation process? Through the examples they shared, it was clear that international lecturers relied on their own agency and on faculty collegiality to adapt effectively to their new environment. Both factors emerged as contributors to the success of the adaptation process. Through collegiality, foreign faculty members received contextrelevant information and emotional support from their peers. Exerting professional agency, lecturers adjusted the class content and adapted their teaching practices to their new environment.

Agency. The international lecturers exercised their agency throughout the adaptation process to search for information, reflect on their experiences and modify their pedagogical practices, but also to make decisions in accordance with their values. Some lecturers exhibited their own agency with regard to teaching changes. They reflected on their teaching philosophy, pedagogical habits and expectations, assessing their relevance in the new context. This selfreflection process enabled them to understand and accept the site's requirements. Taking the example of the assessment guideline in his department, Philip emphasised the relationship between understanding and acceptance: 
I felt like I was going back to teaching in high school. We had to give so many assessments, and I didn't quite see the point in giving so many assessments at university level. But through discussions with colleagues, I began to understand that the idea was that, by the end of the programme, we needed to have brought the students up [to a certain level], so without giving them so many tests, it would have been difficult to measure whether they were now competent in the module.

International lecturers also used their previous experiences in South Africa or abroad (as student or teacher) to adjust to their new site. These past experiences influenced their interpretation of the site context, but could also be activated to prepare lecture contents in a relatively short time. In addition, several lecturers mentioned having upgraded their skills to better match the site needs. For example, they identified training in English language or in their disciplines to improve their subject competency. As reported by lecturers, agency drew on self-reflection and past experiences. International lecturers exercised their agency by critically reflecting on their experiences and incorporating new information received from their peers. It enabled them to accept their new students' learning needs and adjust their pedagogical praxis to the organisational culture. The support of their colleagues was another crucial factor of adaptation and is reviewed in the following paragraphs.

Collegiality. The aspect of collegiality that was emphasised by lecturers was colleagues' support and information sharing. Collegial support facilitated lecturers' understanding of the context and emotional rebalancing after puzzling experiences. Because lecturers did not always understand why things were done in a certain way, they searched for information, explanations and advice from colleagues and supervisors. The community of teachers was praised for providing useful pedagogical advice. Mark explained, 'If there was one topic I was struggling with, in terms of presenting it to the students, I could go and ask ... my supervisor "How can I handle [this topic] so that [students] can understand it properly?"”.

International lecturers reported that the most useful piece of information was usually obtained from colleague(s) from the same country or from the same teaching department. Lecturers who shared the same nationality, cultural background, or teaching experience could 
have been confused by the same aspects of the work in the university. As a result, peer colleagues helped international lecturers make sense of their environment by sharing keys of understanding. As an illustration, Philip reported a discussion with a colleague who had taught in his country of origin. She told him:

Don't expect these students to be the same as those back home. Because they are coming from a different background, so you have to adjust, lower your expectations, and you have to be able to provide them with all the support they need to cope with their work or assignments.

Philip further explained:

Colleagues in the department where I was working also helped in terms of explaining the background that these students were coming from and [the fact that] the effect of the legacy of the apartheid education system was still being felt in South Africa, even so long after 1994.

Lecturers also felt supported through the emotional hurdles of adaptation. Respondents for whom English was not the first language mentioned some struggles to be understood and sometimes respected by students. Steve stressed the supporting role played by his colleagues: 'When you are a foreign lecturer, students ... take you differently because of your accent. So, having someone who could tell you what to do in front of these students ... was very much important to me'. As a result, lecturers emphasised the central role played by colleagues in their adaptation process. Embedded under the collegiality theme, international lecturers received explanations, advice and emotional support from their colleagues which helped them make sense of their experiences. The interrelation between agency and collegiality is finally scrutinised in the last subsection, as peer support enabled lecturers to exercise their agency.

The interrelation between agency and collegiality. Agency and collegiality were often reported jointly as factors of adaptation. Lecturers relied on their colleagues to decode their new environment. Faculty community enabled them to comprehend their students' learning needs in the post-apartheid South African context. It helped them understand the studentcentred learning culture of the university and take appropriate steps to match the site 
requirements. The interrelation is illustrated in Figure 2. It starts with the individual search for information as a result of disorienting experiences. Faculty collegiality provides information, advice and emotional support that are essential in teachers' learning and adaptation. It enables lecturers to design coping and learning strategies that could fit into the site context.

Insert Figure 2 about here

\section{DISCUSSION}

The significance of this study lies in its contribution to the unilateral-bilateral debate related to sociocultural adaptation (Lai et al., 2016; Volet and Jones, 2012). Respondents perceived a unilateral adaptation process whereby they learned and changed several behaviours to meet students' learning needs and administrative requirements. The adaptation process described by participants confirmed the validity of Mezirow's $(1991,2012)$ transformative learning theory in this context. In accordance with the transformative lens, lecturers drew on selfreflection, past experiences and personal capabilities to adjust their teaching practices. The main limitation of this study lies in the diversity of lecturers' experiences and in the fact that volunteer respondents may have had different experiences than those who declined the invitation.

The theoretical contribution of the findings draws on the clarification of the adaptation steps and the revealed prominence of teachers' agency and faculty collegiality in the adaptation process. It sheds new light on the adaptation process of international lecturers in the South African post-apartheid environment. As presented in the literature, collegiality includes teachers' collaboration and exchange of information (Farrell, 2016; Kwiek, 2015) while agency is the capacity of lecturers to be proactive, make decisions and take actions to improve their professional situation within the structure and culture of their new organisation 
(Priestley et al., 2015). Adaptation is not a passive process; it gives lecturers room to exercise their agency in interaction with their new environment (Priestley et al., 2015) and to grow professionally (Clegg, 2011; Volet and Jones, 2012; Tran, 2008). Teachers' agency enables them to reflect on their perceptions and values, make sense of their experiences and act consistently with their renewed frames of reference (Kim, 2008; Tran, 2008; Volet and Jones, 2012). Far from lacking experiences and resources, individuals in transition bring with them capabilities, social capital and funds of knowledge (Moll et al., 1992) that enable them to design coping strategies and consider new possible selves (Clegg, 2011).

The community of teachers has a role to play in the socialisation and adaptation of their international colleagues as best practices can be exchanged within the teaching community (Kwiek, 2015; Manning, 2013; Shah, 2012). Collegiality provides resources to learn and adjust, while agency enables lecturers to take appropriate actions. As a result, both should be promoted in international education settings (Lai et al., 2016). Thus, the practical implications of the study ensue from its relevance to international staff induction programmes (Gopal, 2011; Mizzi, 2017), as lecturers' agency and faculty collegiality can be fostered through different programmes. For example, communities of practice and faculty collaborative projects, including co-teaching, can facilitate teachers' professional learning (Martin-Beltran and Peercy, 2014).

International lecturers were adamant that understanding the historical and political contexts of South Africa was crucial to comprehend the organisational culture and student backgrounds in the university, as the legacy of apartheid still impacts the inequalities and relationships between different racial and cultural groups (Cross and Carpentier, 2009). Hence, staff induction programmes should include information about students' backgrounds and their learning needs to facilitate lecturers' adaptation. This tailored information could 
help them anticipate issues related to the diversity of knowledge and language competencies in class, and enable them to implement inclusive teaching practices.

\section{CONCLUSION}

This study shed new light on the steps of the adaptation process of international lecturers in a South African university and elicited two crucial factors of adaptation: agency and collegiality. These factors appeared interrelated throughout the adaptation process. The findings have direct implications for international staff induction programmes as agency and collegiality could be promoted to facilitate lecturers' sociocultural and pedagogical adaptation. The community of teachers enabled international lecturers to decode the organisational culture of the university but also to understand the specificity of students' learning needs in the South African post-apartheid context. Further studies should consider analysing the opportunities for host and international staff collaboration to facilitate the adaptation process of transnational lecturers as well as encouraging reciprocal learning.

\section{REFERENCES}

Akkerman SF and Bakker A (2011) Boundary crossing and boundary objects. Review of educational research 81(2): 132-169.

Cai L and Hall C (2016) Motivations, expectations, and experiences of expatriate academic staff on an international branch campus in China. Journal of Studies in International Education 20(3): $207-222$.

Clegg S (2011) Cultural capital and agency: connecting critique and curriculum in higher education. British Journal of Sociology of Education 32(1): 93-108. DOI: 10.1080/01425692.2011.527723.

Creswell JW (2012) Educational research: Planning, conducting, and evaluating quantitative and qualitative research. Boston, MA: Pearson Education.

Cross M and Carpentier C (2009) 'New students' in South African higher education: Institutional culture, student performance and the challenge of democratisation. Perspectives in Education 27(1): 6-18.

Cross M, Mhlanga E and Ojo E (2009) Emerging concept of internationalisation in South African higher education: Conversations on local and global exposure at the University of the Witwatersrand (Wits). Journal of studies in international education 15(1): 75-92. 
Deveney B (2007) How well-prepared do international school teachers believe themselves to be for teaching in culturally diverse classrooms? Journal of Research in International Education 6(3): 309-332.

Dongfeng LI (2012) Culture shock and its implications for cross-cultural training and culture teaching. Cross-Cultural Communication 8(4): 70-74.

Farrell M (2016) Collegiality in the workplace. Journal of Library Administration 56(2): 171-179. DOI: 10.1080/01930826.2015.1124696.

Gopal A (2011) Internationalization of higher education: Preparing faculty to teach cross-culturally. International Journal of Teaching \& Learning in Higher Education 23(3): 373-381.

Green W and Myatt P (2011) Telling tales: A narrative research study of the experiences of new international academic staff at an Australian university. International Journal for Academic Development 16(1): 33-44.

Hviid P and Zittoun T (2008) Editorial introduction: Transitions in the process of education. European Journal of Psychology of Education 23(2): 121-130.

Kim YY (2008) Intercultural personhood: Globalization and a way of being. International journal of intercultural relations 32(4): 359-368.

Kishun R (2007) The internationalisation of higher education in South Africa: Progress and challenges. Journal of Studies in International Education 11(3-4): 455-469. DOI: $10.1177 / 1028315307304184$.

Korhonen V and Weil M (2015) The internationalisation of higher education: Perspectives on selfconceptions in teaching. Journal of Research in International Education 14(3): 198-212.

Kwiek M (2015) The unfading power of collegiality? University governance in Poland in a European comparative and quantitative perspective. International Journal of Educational Development 43: 77-89.

Lai C, Li Z and Gong Y (2016) Teacher agency and professional learning in cross-cultural teaching contexts: Accounts of Chinese teachers from international schools in Hong Kong. Teaching and Teacher Education 54: 12-21.

Lodico MG, Spaulding DT and Voegtle KH (2010) Methods in educational research: From theory to practice. San Francisco, CA: Jossey-Bass.

Manning K (2013) Organizational theory in higher education. New York, NY: Routledge.

Martin-Beltran M and Peercy MM (2014) Collaboration to teach English language learners: Opportunities for shared teacher learning. Teachers and teaching: theory and practice 20(6): 721-737. DOI: 10.1080/13540602.2014.885704.

Meho LI (2006) E-mail interviewing in qualitative research: A methodological discussion. Journal of the American society for information science and technology 57(10): 1284-1295.

Mezirow J (1991) Transformative dimensions of adult learning. San Francisco, CA: Jossey-Bass.

Mezirow J (2012) Learning to think like an adult: Core concepts of transformation theory. In: Taylor 
EW and Cranton P (eds) The handbook of transformative learning: Theory, research, and practice. San Francisco, CA: John Wiley \& Sons, pp.73-95.

Mezirow J and Associates (2010) Learning as transformation: Critical perspectives on a theory in progress. San Francisco, CA: Jossey-Bass.

Mizzi RC (2017) Bridging borders: Toward a pedagogy of preparedness for visiting faculty. Journal of Studies in International Education: 1-15.

Moll LC, Amanti C, Neff D, et al. (1992) Funds of knowledge for teaching: Using a qualitative approach to connect homes and classrooms. Theory into practice 31(2): 132-141.

Niyubahwe A, Mukamurera J and Jutras F (2014) L'expérience de transition professionnelle des enseignants de migration récente au Québec. Canadian Journal of Education 37(4): 1.

Parr G (2012) Leading an international teaching practicum: Negotiating tensions in a site of border pedagogy. Asia-Pacific Journal of Teacher Education 40(2): 97-109.

Priestley M, Biesta G and Robinson S (2015) Teacher agency: An ecological approach. London, UK: Bloomsbury Publishing.

Roskell D (2013) Cross-cultural transition: International teachers' experience of 'culture shock'. Journal of Research in International Education 12(2): 155-172.

Shafaei A and Razak NA (2016) Internationalisation of higher education: Conceptualising the antecedents and outcomes of cross-cultural adaptation. Policy Futures in Education 14(6): 701-720.

Shah M (2012) The importance and benefits of teacher collegiality in schools: A literature review. Procedia-Social and Behavioral Sciences 46: 1242-1246.

Sing N (2006) Foreign faculty in South African universities: A case study of the University of South Africa. PhD Thesis, University of the Witwatersrand, South Africa.

Smith K (2013) Overseas flying faculty teaching as a trigger for transformative professional development. International Journal for Academic Development 18(2): 127-138. DOI: 10.1080/1360144X.2012.655280.

Smith K (2014) Exploring flying faculty teaching experiences: Motivations, challenges and opportunities. Studies in Higher Education 39(1): 117-134. DOI:

10.1080/03075079.2011.646259.

Teferra D and Knight J (eds) (2008) Higher education in Africa: The international dimension. The Boston College Center for International Higher Education and the Association of African Universities.

Tran LT (2008) Mutual adaptation of international students and academics for the sustainable development of international education. In: Proceedings of the EDU-COM 2008 International Conference. Sustainability in higher education: Directions for change, pp.524-538.

Van Langenhove L and Harré R (1999) Positioning as the production and use of stereotypes. In: Van Langenhove L and Harré R (eds) Positioning theory: Moral contexts of intentional action, 
Oxford: Blackwell Publishers Ltd., pp.127-137.

Volet S and Jones C (2012) Cultural transitions in higher education: Individual adaptation, transformation and engagement. In: Karabenick S and Urdan T (eds) Transitions across schools and cultures, Bingley: Emerald Group Publishing Limited, pp.241-284.

Walker P (2015) The globalisation of higher education and the sojourner academic: Insights into challenges experienced by newly appointed international academic staff in a UK university. Journal of Research in International Education 14(1): 61-74.

Williams J and Berry A (2016) Boundary crossing and the professional learning of teacher educators in new international contexts. Studying Teacher Education 0(0): 1-17.

Zhou Y and Todman J (2008) Chinese postgraduate students in the UK: A two-way reciprocal adaptation. Journal of International and Intercultural Communication 1(3): 221-243.

\section{Author biography}

Loïse Jeannin is a Post-Doctoral Research Fellow in the Department of Education and Curriculum Studies at the University of Johannesburg. Her research focuses on professional development programs for university lecturers, academic mobility and the adaptation process of international lecturers teaching abroad. She has published several research articles on teacher professional development in international universities. Her Ed.D dissertation with Walden University (United States) was on Professional development needs of faculty members in an international university in Thailand. Being passionate about adult education, Loïse has taught in various international universities in France (Paris), Thailand (Bangkok) and South Africa (Johannesburg). At Stamford International University in Thailand, she contributed to the creation of a blended MBA program to increase students' engagement and facilitate deep learning. She received the "Walden Research Dissemination Award" in 2017 and the "Best Paper Award" at the 4th International Conference on Teaching and Learning (ICTL, Bangkok) in 2013. 


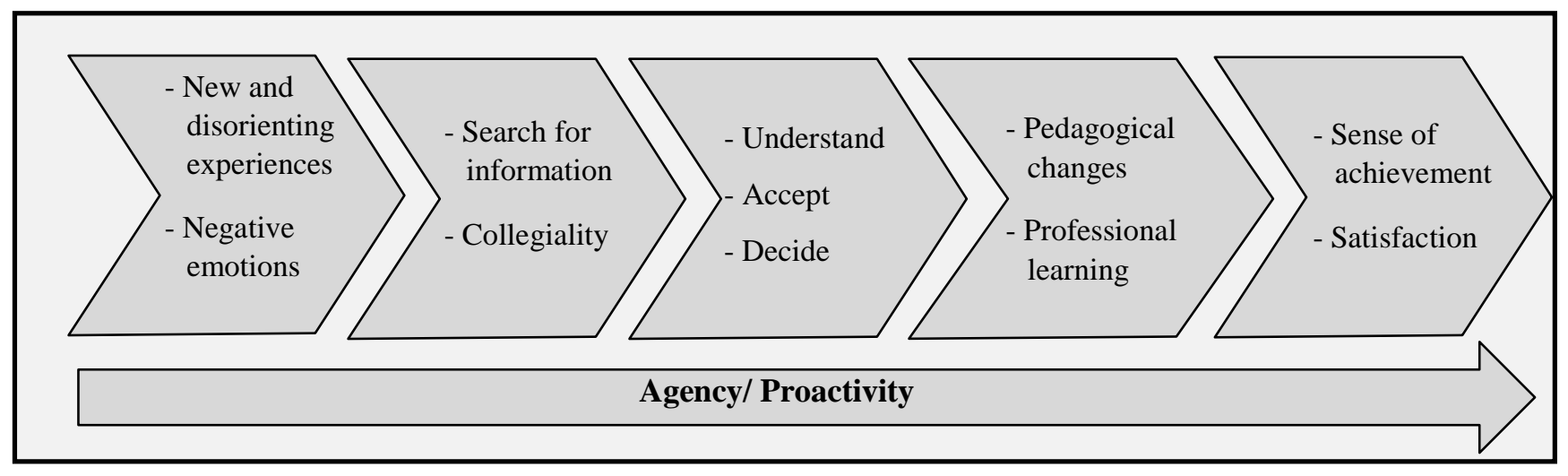

Figure 1. The adaptation process of international lecturers

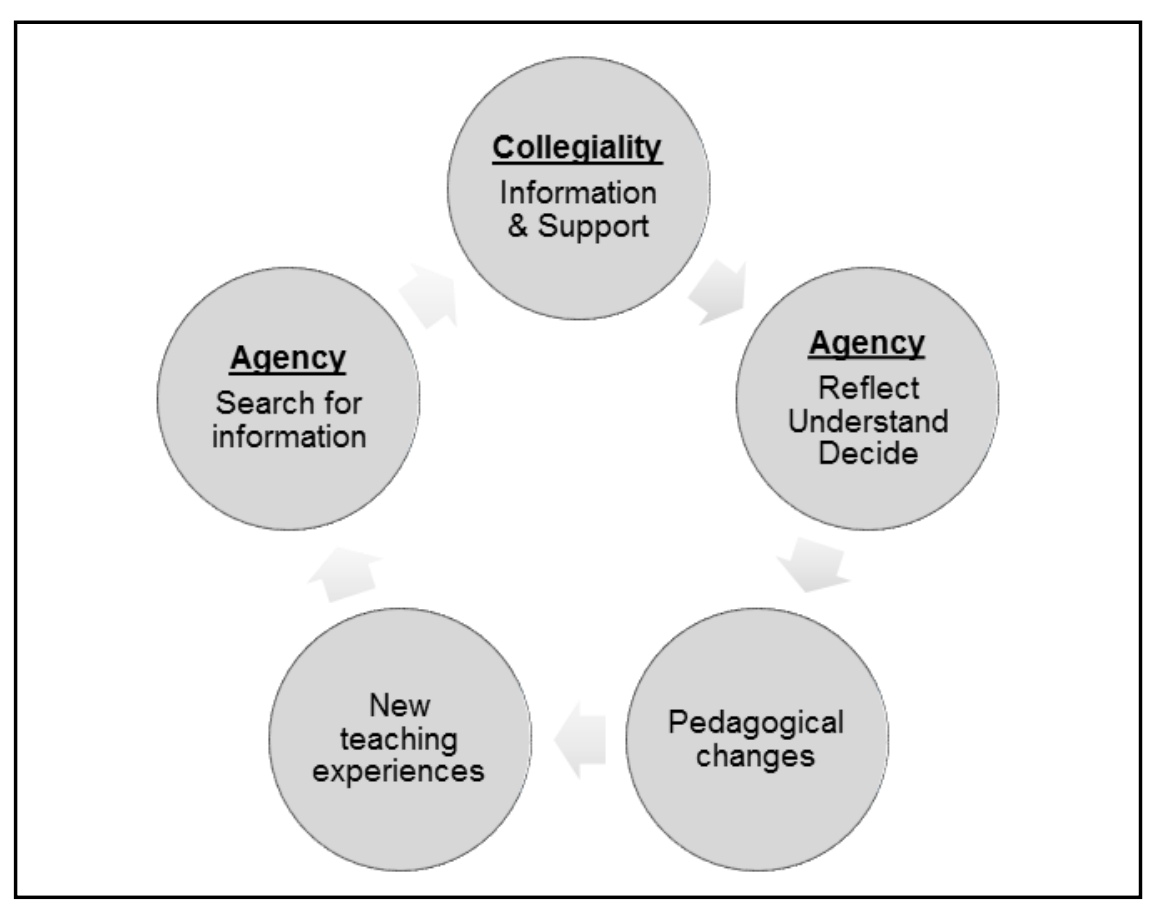

Figure 2. The interrelation between collegiality and agency in the adaptation process of international lecturers 